\title{
Ward-based continuous positive airway pressure (CPAP) in SARS-CoV-2
}

\author{
Authors: Antony Raharja, ${ }^{\mathrm{A}}$ Jonathan TC Kwan, ${ }^{\mathrm{A}}$ Jessica $\mathrm{J}$ Billings, ${ }^{\mathrm{A}}$ Hamid Aminy-Raouf, ${ }^{\mathrm{A}}$ Sudhir Lohani, ${ }^{\mathrm{A}}$
} Burhan Khan ${ }^{\mathrm{A}}$ and Rekha Bhalla ${ }^{\mathrm{A}}$

\begin{tabular}{|c|c|c|c|}
\hline \multirow[b]{3}{*}{ Age, years } & \multicolumn{3}{|c|}{ CPAP as a trial to avoid IMV $(n=38)$} \\
\hline & Avoided IMV $(n=17)$ & Required IMV $(n=21)$ & $p$ value \\
\hline & $54(49-62)$ & $59(51-66)$ & 0.306 \\
\hline Female, n (\%) & $7(41)$ & $6(29)$ & 0.502 \\
\hline BMI, $\mathrm{kg} / \mathrm{m}^{2}$ & $27.7(22.2-33.2)$ & $24.6(23.4-30.2)$ & 0.563 \\
\hline White ethnicity, n ( \%) & $10(59)$ & $14(67)$ & 0.740 \\
\hline \multicolumn{4}{|l|}{ Pre-CPAP ABG analyses } \\
\hline $\mathrm{pH}$ & $7.49(7.47-7.50)$ & $7.46(7.43-7.48)$ & 0.0991 \\
\hline $\mathrm{P}_{\mathrm{a}} \mathrm{CO}_{2}, \mathrm{kPa}$ & $4.8(4.1-5.2)$ & $4.4(4.0-4.7)$ & 0.2422 \\
\hline $\mathrm{Pa}_{\mathrm{a}} \mathrm{O}_{2} / \mathrm{FiO}_{2}, \mathrm{mmHg}$ & $106.3(103.8-121.3)$ & $92.6(74.5-100.6)$ & $0.0154^{*}$ \\
\hline Lactate $\geq 1.5 \mathrm{mmol} / \mathrm{L}, \mathrm{n}(\%)$ & $1(6)$ & $3(15)$ & $>0.99$ \\
\hline \multicolumn{4}{|l|}{ Pre-CPAP $\mathrm{P}_{\mathrm{a}} \mathrm{O}_{2} / \mathrm{FiO}_{2}$} \\
\hline$<100 \mathrm{mmHg}, \mathrm{n}(\%)$ & $3(23)$ & $14(70)$ & $0.0134^{*}$ \\
\hline 100-200 mmHg, n (\%) & $9(69)$ & $6(30)$ & $0.0377^{*}$ \\
\hline$>200 \mathrm{mmHg}, \mathrm{n}(\%)$ & $1(8)$ & $0(0)$ & 0.398 \\
\hline \multicolumn{4}{|l|}{ Laboratory data during CPAP } \\
\hline Lymphocyte, $^{a} \times 10^{9} / \mathrm{L}$ & $0.6(0.4-0.8)$ & $0.5(0.3-0.7)$ & 0.173 \\
\hline D-dimer, ${ }^{b} n g / m L$ & $1,021(378-1,950)$ & $633(392-986)$ & 0.914 \\
\hline Ferritin, ${ }^{b} \mu \mathrm{g} / \mathrm{L}$ & $781(492-1,427)$ & $994(517-1,471)$ & 0.398 \\
\hline $\mathrm{LDH},{ }^{\mathrm{b}} \mathrm{IU} / \mathrm{L}$ & $820(589-944)$ & $1,208(1,000-1,408)$ & $0.0134^{*}$ \\
\hline Troponin, ${ }^{b}$ ng/nL & $9.8(4.8-11.6)$ & $19.4(9.7-35.4)$ & 0.696 \\
\hline $\mathrm{CRP},{ }^{\mathrm{b}} \mathrm{mg} / \mathrm{L}$ & 223 (166-299) & $286(242-378)$ & 0.0829 \\
\hline
\end{tabular}

${ }^{a}=$ lowest measurements obtained while patients were receiving CPAP therapy; ${ }^{b}=$ highest measurements obtained while patients were receiving CPAP therapy; $\mathrm{ABG}=$ arterial blood gas; $\mathrm{BMI}=$ body mass index; $\mathrm{CPAP}=$ continuous positive airway pressure; $\mathrm{CRP}=\mathrm{C}$-reactive protein; $\mathrm{FiO}_{2}=$ fraction of inspired oxygen; $\mathrm{IMV}=$ invasive mechanical ventilation; $\mathrm{LDH}=$ lactate dehydrogenase; $\mathrm{P}_{\mathrm{a}} \mathrm{CO}_{2}=$ partial pressure of arterial carbon dioxide; $\mathrm{P}_{\mathrm{a}} \mathrm{O}_{2}=$ partial pressure of arterial oxygen.

\section{Introduction}

Continuous positive airway pressure (CPAP) therapy had been previously shown to reduce the need for invasive mechanical

Author: A Darent Valley Hospital, Dartford, UK ventilation (IMV) in cardiogenic pulmonary oedema, but evidence of its efficacy in viral-induced respiratory failure is limited and is a subject of debate. ${ }^{1,2}$ An early intubation strategy without trial of non-invasive ventilation (NIV) had been previously suggested, while others have argued for timely, but not premature, intubation. ${ }^{3}$ We retrospectively evaluated the efficacy of CPAP in patients with COVID-19 at a single centre. 
Fig 1. Pre-CPAP $\mathrm{P}_{\mathrm{a}} \mathrm{O}_{2} / \mathrm{FiO}_{2}$ and $\mathrm{LDH}$ levels in patients who avoided IMV $\left(P_{\text {CPAP }}\right)$ and those who required IMV $\left(\mathrm{P}_{\text {IMV }}\right)$. Differences between the two groups were compared using a MannWhitney $\mathrm{U}$ test. $\mathrm{CPAP}=$ continuous positive airway pressure; IMV = invasive mechanical ventilation; $\mathrm{LDH}=$ lactate dehydrogenase; pre-CPAP $\mathrm{P}_{\mathrm{a}} \mathrm{O}_{2} / \mathrm{FiO}_{2}=$ ratio of partial pressure of arterial oxygen to a fraction of inspired oxygen preceding CPAP commencement.
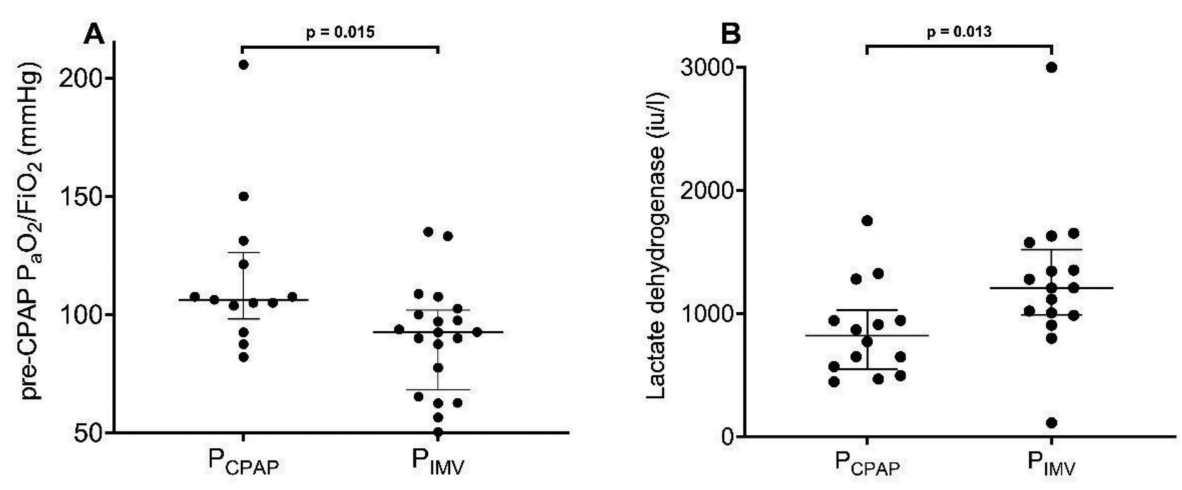

\section{Methods}

We reviewed notes of consecutive patients between 21 March and 23 April 2020. Inclusion criteria were laboratory-confirmed diagnosis of SARS-CoV-2 and CPAP therapy. Exclusion criteria were $<16$ years old, pregnancy, acute-on-chronic hypercapnic respiratory failure and acute respiratory failure from an alternative diagnosis to SARS-CoV-2. Patient characteristics, laboratory results, rates of intubation and mortality were recorded.

Unpaired parametric and non-parametric data were compared with an unpaired two-sample $t$ test or MannWhitney test, respectively. Fisher's exact test was used for categorical variables. All statistical tests were two-tailed. Analyses were performed with GraphPad Prism 8.4.2 (GraphPad Software, San Diego, USA).

\section{Results and discussion}

Sixty patients received CPAP during the study period; 52 met study criteria. Mean age was $61.4( \pm 14.1)$ years, 17 (33\%) were females, 14 (27\%) non-White Caucasians, median body mass index (BMI) $27.7 \mathrm{~kg} / \mathrm{m}^{2}$ (interquartile range (IQR) 23.8-32.2 $\mathrm{kg} / \mathrm{m}^{2}$ ) and frailty scale $2(1-3)$. Before CPAP, $46(89 \%)$ patients required $\mathrm{FiO}_{2} \geq 0.60$ to maintain target oxygenation and the remaining patients were commenced on CPAP due to respiratory rates $>35$ breaths $/ \mathrm{min}$ despite $\mathrm{FiO}_{2} \geq 0.35$.

Thirty-eight patients received CPAP as a trial to avoid IMV; 21 (55\%) eventually required IMV after 38 (21-67) hours, while 17 (45\%) avoided IMV after 108 (71-209) hours. Patients requiring a non-rebreather oxygen mask pre-CPAP were unlikely to avoid intubation; seven of nine (78\%) failed trial of CPAP. Patients who avoided intubation $\left(\mathrm{P}_{\mathrm{CPAP}}\right)$ had a significantly higher preCPAP $\mathrm{P}_{\mathrm{a}} \mathrm{O}_{2} / \mathrm{FiO}_{2}$ and lower lactate dehydrogenase (LDH) than those who required IMV $\left(\mathrm{P}_{\text {IMV }}\right.$ ) (Table 1 , Fig 1). $\mathrm{P}_{\mathrm{a}} \mathrm{O}_{2} / \mathrm{FiO}_{2}$ on PEEP (positive end-expiratory pressure) $\geq 5 \mathrm{~cm} \mathrm{H}_{2} \mathrm{O}$ in $\mathrm{P}_{\mathrm{CPAP}}$ was higher than $\mathrm{P}_{\mathrm{IMV}}$ : median $\mathrm{P}_{\mathrm{a}} \mathrm{O}_{2} / \mathrm{FiO}_{2} 120.0$ (104.0-228.8) vs $85.0(80.2-92.0) \mathrm{mmHg}, \mathrm{p}=0.024$.

Four of $14(29 \%)$ patients who received CPAP as the ceiling of treatment were successfully weaned off CPAP after 152 (128206) hours. Overall, in-hospital mortality was 21/52 (40\%); $11 / 38(29 \%)$ in the trial to avoid IMV group, and $10 / 14(71 \%)$ in the ceiling of treatment group. Complications were uncommon; one $(2 \%)$ patient developed a pneumothorax.
Early intubation strategy was previously fiercely advocated due to concerns of exceedingly high NIV failure rate in MERS, infection transmission risks and poorer outcomes with delayed intubation. ${ }^{4-6}$ In a non-SARS-CoV-2 population, the LUNGSAFE study showed higher ICU mortality with NIV use in patients with $\mathrm{P}_{\mathrm{a}} \mathrm{O}_{2} / \mathrm{FiO}_{2}<150 \mathrm{mmHg}$ compared with early intubation. ${ }^{6}$ Data in SARS-CoV-2 are not available. Whether intubating patients after CPAP failure contributed to any excess mortality could not be inferred from this study and ought to be investigated further.

\section{Conclusion}

Ward-based CPAP was feasible and may reduce the need for intubation in patients with severe SARS-CoV-2 by $45 \%$. Patients with high LDH and pre-CPAP $\mathrm{P}_{\mathrm{a}} \mathrm{O}_{2}<100$ were unlikely to avoid intubation with trial of CPAP. Larger studies should confirm the efficacy of CPAP therapy and investigate predictors of successful CPAP therapy in SARSCoV-2 patients.

\section{Conflicts of interest}

None declared.

\section{References}

1 Masip J, Roque M, Sánchez B et al. Noninvasive ventilation in acute cardiogenic pulmonary edema: systematic review and metaanalysis. JAMA 2005;294:3124-30.

2 McEnery T, Gough C, Costello RW. COVID-19: Respiratory support outside the intensive care unit. Lancet Respir Med 2020;8:538-9.

3 Meng L, Qiu H, Wan L et al. Intubation and ventilation amid the COVID-19 outbreak: Wuhan's experience. Anesthesiology 2020;132:1317-32.

4 Alraddadi BM, Qushmaq I, Al-Hameed FM et al. Noninvasive ventilation in critically ill patients with the Middle East respiratory syndrome. Influenza Other Respir Viruses 2019;13:382-90.

5 Arulkumaran N, Brealey D, Howell D, Singer M. Use of non-invasive ventilation for patients with COVID-19: a cause for concern? Lancet Respir Med 2020;8:e45.

6 Bellani G, Laffey JG, Pham T et al. Noninvasive ventilation of patients with acute respiratory distress syndrome. Insights from the LUNG SAFE study. Am J Respir Crit Care Med 2017;195:67-77. 